\title{
Análise qualitativa dos efeitos de argilosidade em perfis do poço estratigráfico Delta 1, Bacia de Campos, RJ.
}

\author{
Luna $^{1}$, J.L.; Perosi ${ }^{1}$, F.A; Ribeiro ${ }^{1}$, M.G.S; Borghi, L ${ }^{2}$ \\ 1 - Laboratório de Geofísica e Petrofísica (LAGEP),Departamento de Geologia, Instituto de Geociências, CCMN - UFRJ \\ 2 - Laboratório de Geologia Sedimentar (LAGESED), Departamento de Geologia, Instituto de Geociências, CCMN - UFRJ
}

Copyright 2014, SBGf - Sociedade Brasileira de Geofísica

Este texto foi preparado para a apresentação no VI Simpósio Brasileiro de Geofísica, Porto Alegre, 14 a 16 de outubro de 2014. Seu conteúdo foi revisado pelo Comitê Técnico do VI SimBGf, mas não necessariamente representa a opinião da SBGf ou de seus associados. É proibida a reprodução total ou parcial deste material para propósitos comerciais sem prévia autorização da SBGf.

\section{Resumo}

Através do conhecimento de propriedades de rochas, é possível, junto com a análise de medidas indiretas, obter insights que facilitam a caracterização de reservatórios.

Com a utilização de perfis de poço associados a conhecimentos da litologia local (descrição de testemunho) foi possível analisar os efeitos de argilosidade na resposta geofísica obtida em uma zona de reservatório de água, sendo possível obter insights sobre a distribuição das argilas nesta zona e seus efeitos em características de interesse na avaliação de reservatórios, como o valor de saturação de água e efeitos da distribuição da argila em características como a permeabilidade e a espessura de gargantas de poros.

\section{Introdução}

As propriedades das rochas permitem identificar parâmetros de interesse e a ganhar alguns insights sobre medições indiretas. A forma porosa que constitui a rocha reservatório é fundamental para avaliação das características de uma reserva. Todavia o grau de argila presente na rocha e no meio poroso é determinado como o grau de impureza de uma rocha, o que é um parâmetro importante para definição litológica da formação, pois sua presença afeta substancialmente a leitura de alguns perfis, além de interferir em parâmetros petrofísicos importantes como a permeabilidade e a tortuosidade. As propriedades de CTC e de expansão das argilas influenciam as condições de previsão e de dano a formação assim como a interpretação dos registros dos perfis de poços. Esta condição das argilas foi estudada detalhadamente por Civan, 1999 que apontou em seus testes laboratoriais condições de reservatório que podem variar, obtendo resultados como a condição do efeito de concentrações variáveis da solução aquosa, a ser incorporada a simulação de dano de formação. Segundo Ladd (1960) os cátions trocáveis não entram em movimento devido a aplicação de um campo elétrico negativo. Assim, o campo elétrico atua como uma membrana semi-permeável a medida que permite que a água penetre entre a dupla camada, mas não irá permitir que os cátions deixem a mesma. Desta forma, a quantidade de íons concentrados na dupla camada entre as partículas de argila é mais elevada do que a quantidade de fluido aquoso presente no poro. Esse fenômeno cria uma pressão osmótica repulsiva entre as partículas de argila. Como resultado, a distância entre as partículas aumenta. Desta forma, a pressão osmótica é a diferença de concentração total de íons entre a argila de dupla camada e o poro de fluido circundante.

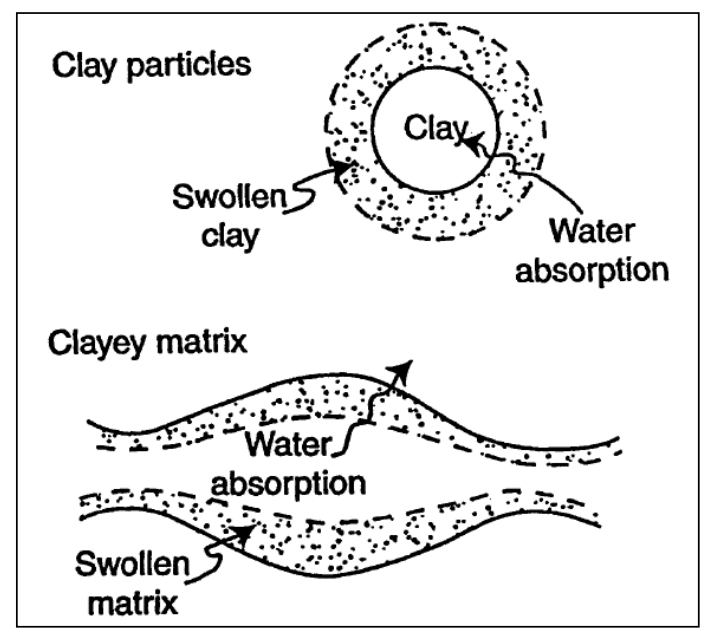

Figura 1: Modelo de absorção de água por particulas argilosas e por matriz argilosa (retirado de Civan, 1999).

Segundo Abe, 1999 o comportamento mecânico de argilas é fortemente afetado pelas condições de temperatura e pressão, assim, para a analise da deformação e da estabilidade de regiões argilosas com certa carga térmica é necessário considerar a lei constitutiva termo-viscoplástica, que descreve a temperatura e a dependência das característica da argila associando com o tempo. A consolidação de argilas saturadas com água segundo as variações de temperatura é definida pelo fenômeno que envolve a transferência de calor, a difusão de fluxo de fluido nos poros e a condição estrutural da formação.

Das análises de uma ampla variedade de argilas definese a possibilidade de que a expansão das argilas pode causar diferença nos valores de velocidade sônica. A ilita, por exemplo, não gera muita diferença devido as suas características, sendo provavelmente uma argila com maior facilidade para o desenvolvimento decorrelações. Já os cristais imperfeitos e as variações de composição podem explicar parte da diferença a ser corrigida para as condições de tamanho de argila/mineral argila, o que piora as análises (Keith, 1996). 


\section{Metodologia/ Problema Investigado}

Para aquisição dos dados utilizou-se as ferramentas de perfilagem (wireline) da empresa Robertson Geolloging® pertencente ao Laboratório de Geofísica e Petrofísica LAGEP vinculado ao Departamento de Geologia, Instituto de Geociências (IGEO/ CCMN) da Universidade Federal do Rio de Janeiro (UFRJ).Os dados trabalhados foram registrados através do software de aquisição WinLogger® que através de um transdutor (Micrologger®) é interfaceado com o guincho/ferramenta, e que aciona a ferramenta. Neste sentido utilizou-se as ferramentas de Cáliper com 3 pernas localizadas em sua extremidade inferior e com comprimento de 2.11 metros, sendo capaz de ler radialmente diâmetros na faixa de 40 a 300 milímetros e com velocidade operacional na faixa de 5 $8 \mathrm{~m} / \mathrm{min}$. A ferramenta Eletric Log que possui 2.5 metros de comprimento e diâmetro de $44 \mathrm{~mm}$ e uma velocidade típica de aquisição de aproximadamente $5 \mathrm{~m} / \mathrm{min}$. Realiza medidas de resistividade normal (curta e longa), potencial espontâneo, gama natural e resistência elétrica da parede do poço. Possui 3 eletrodos sendo capaz de realizar aquisição da resistividade normal curta a um valor radial máximo de $36 \mathrm{~cm}$ e da resistividade normal longa com capacidade de penetração radial máxima de $137 \mathrm{~cm}$. Para ambos os perfis a resistividade máxima permitida é de $10 \mathrm{~K}$ ohm.m. Sendo capaz de fornecer a leitura da resistência rasa (parede do poço) com valor máximo de $10 \mathrm{~K}$ ohm. A leitura de potencial espontâneo é realizada dentro de um intervalo de -1 a 1 Volts. Todas as medidas operacionais, como isolamento elétrico do "cable head" e dos dez primeiros metros foram devidamente realizadas. Outra ferramenta utilizada foi a Slim Induction com uma profundidade de investigação radial de $57.5 \mathrm{~cm}$ com a aquisição podendo ser realizada durante a descida ou subida com velocidade típica de operação de $6 \mathrm{~m} / \mathrm{min}$. Seu intervalo de condutividade é de 2 a $3.000 \mathrm{mS} / \mathrm{m}$. O registro sônico foi obtido pela ferramenta Three Receiver Sonic que possui 3 receptores e um transmissor (operando a $20 \mathrm{KHz}$ ), sendo capaz de realizar aquisições da onda completa. A sua velocidade de aquisição é considerada baixa, operando a $2 \mathrm{~m} / \mathrm{min}$ com dimensões de $245 \mathrm{~cm}$ de comprimento e $0.45 \mathrm{~cm}$ de espessura, com peso de $15 \mathrm{~kg}$. A ferramenta de Temperatura e Condutividade de Fluido possui dimensões de $163 \mathrm{~cm}$ de comprimento, um diâmetro de $0.38 \mathrm{~cm}$ e peso de $8 \mathrm{~kg}$. A sua velocidade de aquisição é de $3 \mathrm{~m} / \mathrm{min}$. Todas estas ferramentas possuem limite de pressão máxima de $3000 \mathrm{PSI}$ e temperatura de $70^{\circ} \mathrm{C}$.

\section{Resultados}

A descrição dos testemunhos do poço Delta 1 (Bacia de Campos em Farol de São Tomé), revela que o poço apresenta seções sequenciadas com estratos de arenito médio a grosso, areias grossa mal selecionada com muita argila, arenito fino argiloso e friável e argilito arenoso, estas seções variam de espessuras que vão de $10 \mathrm{~cm}$ à $375 \mathrm{~cm}$ com muita intercalações. A profundidade de $150 \mathrm{~m}$ a $160 \mathrm{~m}$ é a que mais nos chama atenção quanto à resposta dos perfis, visto que o perfil de SP mostra uma deflexão para a esquerda definido por uma zona onde o filtrado é mais doce que a água da formação, contudo a formação (rocha + fluido) apresenta resistividade elevada na leitura da ferramenta mais longa, o que determina zona de água de baixa salinidade. A ferramenta sônica registrou na profundidade de $156 \mathrm{~m}$ à $159 \mathrm{~m}$ uma série de deflexões "ruidosas" visto que neste intervalo, possivelmente os poros sejam afetados por argilas com água adsorvida com efeito anisotrópico e com extrapolação. No entanto, como formações argilosas normalmente molhadas interferem na medida da velocidade, uma vez que as partículas de argila se apresentam de forma anisotrópica e pequenas quantidades não detectadas estejam alinhadas com a baixa porosidade. A presença da não linearidade dos registros sônicos pode estar relacionada com a não linearidade da quantidade de argila em transição a partir de grão-suportado para uma condição de rocha matriz suportada por argila (Figuras 2 e 3 ).

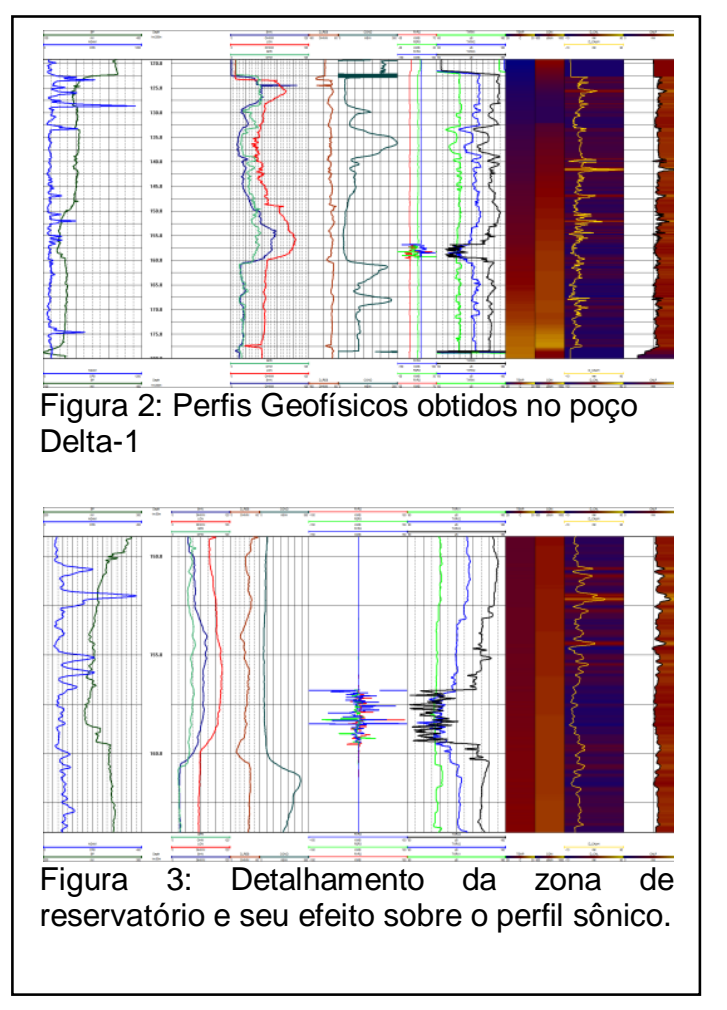

\section{Discussão e Conclusões}

Os estratos muito argilosos e com muita presença de argila intercalada são alinhados durante o processo de compactação gerando uma porosidade de certa forma também alinhada e com isto uma velocidade diferenciada quando entreposta, fazendo com que a velocidade da onda seja menor para algumas profundidades dos registros. Todavia, no intervalo de $157 \mathrm{~m}$ à $159 \mathrm{~m}$, há a presença de areia média a grossa, mal selecionada com alguns seixos e um percentual de argila variando entre 5 a $10 \%$. Para tal reservatório de água com algum percentual de argila e muita areia pode-se perceber 0 efeito do ambiente no sônico, sendo interessante notar que neste caso a resposta sônica está relacionado com a condição do fluido presente, que por sua vez afetaria o 
cálculo da saturação de água. Considerando os arenitos presentes no intervalo de $150 \mathrm{~m}$ a $160 \mathrm{~m}$, a parte superior desta areia apresentam valores de $R G=a 25$ GPS, $\Delta t=60, R_{\text {(raso) }}=54$ ohm.m e Rt $=75$ ohm.m que gera um $\mathrm{Di} \cong 25 \mathrm{~cm}$. Naturalmente, quando as partículas de argila se apresentam disseminadas nos poros tipo interpartículas, tendem a ser bem espalhadas, influenciando na permeabilidade e no diâmetro da garganta de poro, o que gera uma variação de velocidade em poros com grande volume de água e esta relação gera consequentemente uma variação anisotrópica.

\section{Agradecimentos}

Ao PRH-18/ANP pela bolsa de doutorado, a Petrobrás pelo apoio a compra dos equipamentos utilizados e a Chevron (Projeto Delta) pelo poço Delta-1 e a disponibilização dos dados.

\section{Referências}

Abe, Nobuharu, 1999: Thermo-Viscoplastic Modeling of Temperature Dependent Behavior of Clays. Osaka University, Osaka, Japan.

Civan, Faruk, 1999: Interpretation and Correlations of Clay Swelling Measurements. Society of Petroleum Engineers, SPE Mid-Continent Operations Symposium, Oklahoma City, Oklahoma, 28-31 March 1999.

Katahara, Keith W.,1996 : Clay Mineral Elastic Properties. ARC0 Exploration and Production Technology.

Ladd, C.C., 1960: "Mechanisms of Swelling by Compacted Clay," Highway Research Board, Bulletin 245, National Academy of Sciences-National Research Council, Publication 731, Washington,D.C. 10-26. 